\title{
KONSTRUKSI TEKNIK KONSELING BERBASIS BUDAYA MODEL KIPAS UNTUK MENINGKATKAN KECAKAPAN SOSIAL DAN KEMATANGAN KARIER SISWA
}

\author{
Nisa Ariantini ${ }^{1}$, Muhammad Nikman Naser ${ }^{2}$, Ahmad Hanafi ${ }^{3}$ \\ Universitas Borneo Tarakan ${ }^{1}$,IAIN Bengkulu², Pascasarjana Universitas Negeri Malang ${ }^{3}$ \\ ariantiny.nisa@borneo.ac.id¹, nikmanmuhammad2015@gmail.com², hanafizempal@gmail.com³
}

\section{ABSTRAK}

Setiap budaya memiliki sistem nilai yang dapat menjadi strategi dan penguatan bagi siswa dalam menyelesaikan tugas perkembangan khususnya bidang sosial dan karier. Problematik yang menjadi sorotan pada generasi milenal saat ini ialah siswa kurang memiliki kecakapan hidup sosial yang produktif dan belum optimalnya kematangan karier untuk masa akan datang. Pendekatan konseling berbasis budaya model KIPAS dapat menjadi alternatif solusi untuk mengatasi problematik tersebut, karena sesuai dengan konteks budaya Indonesia. Tujuan penelitian ini untuk mendeskripsikan serta mengkonstruksikan teknik yang akan diterapkan dalam proses konseling berbasis budaya berupa permainan rakyat yang memiliki nilai, falsafah hidup dan pepatah budaya nusantara. Penelitian ini menggunakan pendekatan kualitatif dengan desain penelitian deskriptif kualitatif. Hasil penelitian dimana sistem nilai yang dianut oleh masyarakat Bengkulu, Tarakan, Madura khususnya dan Indonesia secara umum sejatinya dapat digunakan sebagai teknik konseling berbasis budaya sebagai upaya membantu mengatasi problematik sosial dan karier siswa dalam segi praktis-lapangan.

\section{Kata Kunci}

kecakapan sosial, kematangan karier konstruksi tekhnik, konseling model

KIPAS

Cara mengutip: Ariantini, N., Naser, M.N., \& Hanafi, A. (2019) Konstruksi Teknik Konseling Berbasis Budaya Model Kipas Untuk Meningkatkan Kecakapan Sosial Dan Kematangan Karier Siswa. Jurnal Nusantara of Research, 6(1) 26-32.

\section{PENDAHULUAN}

Hasil studi lapangan yang dilakukan pada bulan Mei 2017 melalui proses wawancara dengan guru BK di SMK Negeri Se Kota Bengkulu, diperoleh gambaran umum permasalahan terkait kematangan karier diantaranya: (1) siswa kurang memiliki perencanaan masa depan yang realistis, ditunjukkan dengan merancang pekerjaan yang tidak sesuai keadaan dirinya, (2) kurangnya motivasi diri untuk berkembang dan sukses, (3) persiapan karier yang belum optimal (4) tidak percaya dengan kemampuan yang dimiliki dan ragu-ragu dalam pengambilan keputusan karier, (5) belum dapat menyusun alternatif pilihan karier sebagai antisipasi peluang karier kedepan.

Mengacu pada hasil studi lapangan lainnya yang dilakukan di Kota Tarakan Provinsi Kalimantan Utara, diperoleh fenomena terkait dengan kecakapan sosial siswa sekolah menengah diantaranya: 1) pola komunikasi yang kurang baik, 2) kurangnya rasa saling menghargai, 3) ketidakmampuan siswa bersikap tegas menyikapi suatu permasalahan. Berdasarkan fenomena-fenomena tersebut, tenaga pendidik dalam hal ini guru BK/konselor 
harus siap dan sigap untuk membantu mengatasi hal tersebut sesuai peranannya sebagai helping profession.

Indonesia merupakan negara besar yang terdiri dari ribuan pulau besar dan kecil yang didiami oleh masyarakat dari berbagai macam agama, suku, budaya, dan masyarakat hukum adat. Wilayah geografis Indonesia didiami oleh sejumlah suku besar, yaitu: Jawa, Minangkabau, Batak, Bugis, Madura (Nizhamul, 2009), serta ratusan suku-suku lainnya. Masing-masing suku, budaya, dan masyarakat hukum adat tersebut hidup dan berkembang berdasarkan kesadaran nilai yang berbeda-beda, unik dan cenderung menganut falsafah hidup masyarakat Timur yang penuh tata karma dan agamis. Hal yang menarik dari keberagaman tersebut, perbedaan budaya masyarakat Indonesia mampu diikat dalam suatu kesatuan dalam bingkai Negara Kesatuan Republik Indonesia.

Metode layanan bimbingan dan konseling di sekolah menengah maupun kejuruan pada umumnya masih menggunakan model-model pendekatan barat yang pada kenyataannya ketika diterapkan oleh guru BK mengalami kendala, seperti terbebani dengan metode yang bersifat teoritis dari pada praktis. Guru BK belum menerapkan kerangka kerja/model konseling berbasis budaya Indonesia, sehingga tanpa disadari berdampak pada hasil yang kurang produktif dan kurang bermartabat dalam pandangan siswa serta para orangtua.

Penjelasan ini didukung oleh McCluskie (2010) yang menunjukkan bahwa di Amerika Serikat, beberapa teori konseling barat secara detail telah dikritisi atas kelemahan dalam implementasinya sehingga, Guru BK dalam hal ini harus lebih cermat memilih dan menggunakan model konseling yang sesuai dengan karakteritstik dan budaya siswa. Konselor diharapkan tidak sekedar mempelajari dan mempraktikkan teori dan pendekatan yang dikemukakan oleh Barat, namun juga mampu merumuskan gubahan-gubahan tersendiri tentang bimbingan dan konseling Indonesia, salah satunya dengan menggunakan pendekatan Konseling Model KIPAS yang dapat digunakan sebagai teknik konseling bebasis kekhasan budaya nusantara.

Pendekatan konseling model KIPAS (Konseling, Intensif, Progresif, Adaptif, Struktur) merupakan kerangka kerja konseling berbasis budaya kontemporer yang mulai tersyiar di penjuru pulau di Indonesia. Kekhasan pendekatan ini ialah tidak memandang siswa/konseli sebagai pribadi yang bermasalah/tidak sehat namun pribadi yang memiliki potensi, berupaya membantu mengkaji dan mengembangkan aset-aset positif dalam diri konseli, dan berkolaborasi dengan pihak-pihak yang dapat mendukung kemajuan siswa/konseli tersebut (Mappiare-AT.,2013a; 2013b; 2017).

Konseling model KIPAS hakikatnya merupakan wujud praksis dari PostmodernKonstruksionis. Postmodern-Konstruksionis adalah perpaduan antara Konstrusksionisme Sosial dan Konstruktivisme Psikologis (Rigazio-DiGiilio, 2001) yakni suatu kerangka kerja yang dirancang dan disusun agar dapat beradaptasi dengan konteks lingkungan sosialbudaya (struktur dan pranata) sekolah dan keadaan psikologis siswa. 
Beberapa strategi modifikasi KIPAS yang tersedia diantaranya: kelola-diri dan rekonstruksi pribadi, immunisasi-diri dan internalisasi nilai-budaya, pemberdayaan (empowering), analisis-diri dan situasi, dan sensitisasi sosial (sarasehan). Dari beberapa strategi yang sekaligus menjadi teknik dalam penelitian ini difokuskan pada pemberdayaan (empowering) yakni menggunakan permainan-permainan lokal yang telah dimodifikasi dan internalisasi nilai-nilai budaya tersirat dalam pepatah serta falsafah budaya. Perpaduan antara budaya Sumatera, Kalimantan, dan Madura bersinergi menjadi suatu teknik dalam upaya mengentaskan problematik bidang sosial dan karier siswa.

\section{METODE}

Penelitian ini menggunakan pendekatan kualitatif dengan desain penelitian deskriptif kualitatif, sehingga laporan penelitiannya disusun dalam bentuk narasi yang bersifat deskriptif dan mendalam yang menunjukkan ciri-ciri naturalistic dan otentik karena dalam penelitian ini akan lebih mengutamakan proses dan makna (Bogdan, 1990). Secara spesifik penelitian ini menggunakan pendekatan hermeneutik. Hermeneutik merupakan kajian dalam menginterpretasikan makna dalam suatu teks baik secara teks maupun tersirat. Hal ini diperkuat oleh (Strong, 2008: 117-128) yang menegaskan bahwa antara hermeneutik dan konseling sangat berkaitan dalam suatu kajian ilmu rumpun sosial.

Mappiare-AT (2013: 118) menjelaskan bahwa hakikat hermeneutik merupakan peluang kritik yang lebih produktif dalam suatu karya dengan maksud membenarkan ataupun menggali landasan fundamental dibalik karya tersebut. Bentuk dari penelitian ini adalah mendeskripsikan, menganalisis serta menafsirkan nilai-nilai permainan Tangkap Lokam di Tarakan, budaya kerja yang digali dari budaya suku melayu Bengkulu yaitu nilai-nilai pepatah dan pengharapan masyarakat dan falsafah hidup etnis Madura. Hasil dari kajian ini dapat menjadi rujukan dalam penerapan strategi konseling berbasis budaya.

Tahap-tahap yang dilakukan dalam penelitian ini melalui tahapan semantic,tahap refleksif dan tahap eksistensi (Ricoeur, 2003: 210-214). Miles (Sugiono 2010: 337) menuturkan ada tiga langkah yang ditempuh dalam menganalisis data, yaitu mereduksi data, menyajikan data, dan verifikasi data. Selanjutnya dilakukan pengecekkan keabsahan data dengan teknik triangulasi (pemeriksaan data dengan memanfaatkan sesuatu yang lain di luar data untuk keperluan pengecekkan atau sebagai pembanding terhadap data tersebut).

\section{HASIL}

Berdasarkan data dan temuan penelitian, berikut akan dibahas hasil temuan tersebut secara kongkrit. Kecakapan sosial merupakan kemampuan seseorang dalam menjalin hubungan komunikasi, menjalin kerjasama, saling menghargai dalam proses interaksi di lingkungan sosial. Adapun konten kecakapan sosial yang berkembang melalui penerapan permainan Tangkap Lokam, sebagai berikut: (1) Kerjasama, yaitu kegiatan interaksi untuk melaksanakan suatu kegiatan sesuai dengan peran dan tugas, kepatuhan melaksanakan kegiatan sesuai dengan aturan, saling menjalin kolaborasi antar anggota kelompok, dan berpartisipasi dalam kelompok, (2) Kepemimpinan, yaitu kemampuan seseorang dalam memberikan pengaruh atau mengatur suatu kelompok untuk mencapai 
tujuan, baik dengan melakukan diskusi, menerima masukan anggota kelompok, memberikan kesempatan anggota menyampaikan pendapat, atau bertindak tegas untuk kelompok, serta mengatur segala urusan kelompok, (3) Asertif, yaitu kemampuan seseorang mengungkapkan secara jujur dalam menyampaikan pendapatnya, secara apa adanya terkait kesetujuan atau pun ketidak setujuan pendapat, mampu berpikir kritis sebagai bahan diskusi kelompok, mampu menyampaikan pendapat secara ekspresif, serta mampu menyampaikan secara tegas ketidaksetujuan yang disertai dengan penjelasannya, (4) Bertanggung Jawab, yaitu kemampuan seseorang dalam melaksanakan tugasnya secara baik dan terselesaikan, mampu memberikan pilihan-pilihan yang dapat dilakukan, serta memiliki sikap kepedulian untuk membantu tugas orang lain dan (5) Saling Mempercayai, yaitu kemampuan seseorang memberikan keyakinan dalam menjalin proses interaksi, menghargai keputusan orang lain, dan memberikan kesempatan melaksanakan aktivitas.

Hasil penelaahan pepatah dan pengharapan orangtua suku melayu Bengkulu yang telah dilakukan, maka diperoleh nilai-nilai ajaran dalam memandang kesuksesan karier seseorang diantaranya: (1) "Ringan tulang bereklah perut" artinya siapa yang perduli dengan masa depannya, berusaha dan bekerja keras, hidupnya pasti akan tenang dan berkecukupan serta dapat mengangkat harkat martabat keluarga. (2) "Dimano bumi dipijak disitu langit dijunjung" artinya sikap atau hal-hal yang kurang menguntungkan perlu diubah dan dikembangkan agar menjadi manusia yang terampil dalam segi intelegensi, pekerjaan dan kehidupan sosial. Lebih jelas lagi diartikan bahwa dimanapun kita berada harus mampu menyesuaikan diri di tempat bekerja, kreatif dan pandai mengambil hati agar selamat, disenangi dan sukses.(3) "Jangan kau idak jadi orang" artinya jangan kamu tidak menjadi orang, orang dalam hal ini ialah manusia yang cerdas, berhasil, dan menjadi kebanggaan keluarga. Pesan ini disampaikan oleh orangtua kepada anak-anaknya sebagai motivasi agar kehidupan mereka dapat jauh lebih baik dari orangtuanya. (4) "Bere secupak ikan sejerek, madar" artinya suatu keberhasilan dan kepuasaan yang luar biasa atas nikmat yang diberikan oleh Tuhan sang pencipta, apabila mampu memenuhi kebutuhan ekonomi individu dan keluarga yang dihidupi, cukup untuk makan, cukup untuk membeli lauk pauk, dan bahagia (sehat dan bisa istirahat dengan nyenyak). Pepatah ini mengisyaratkan bahwa, kebahagiaan tidak hanya diukur dari uang namun kebahagiaan hati dan mampu menikmati hidup atas hasil yang didapat meskipun sedikit.

Disisi lain hasil kajian mengenai falsafah hidup orang Madura ialah memiliki kekuatan, ketangguhan dalam menjalani aktivitas kesaharian dalam bekerja berpegang pada nilai-nilai luhur. Terbentuknya jiwa pekerja yang tangguh pantang menyerah adalah wujud kegigihan dalam bekerja. Sabar dalam berbuat sesuatu dengan diringi kegigihan dan tekun tanpa melihat bentuk pekerjaan yang dijalani sehingga, hal tersebut membentuk kekuatan dalam diri yang selalu mendorong keinginan dalam melakukan sesuatu. Mentalitas bekerja orang madura adalah ulet yakni mampu menunjukan kesuksesan di berbagai bidang. Mulai dari berdagang/wirausaha/bisnis, bertani, sampai menjadi pejabat strategis di kancah nasional. Semua itu wujud atas keuletan dalam berusaha, berikhtiar. Etos kerja yang 
dilandaskan pada semangat religiusitas. Memegang nilai religi pada aspek-kehihupan sebagai landasan nilai yang diberangi dengan usaha manusia untuk mencapai tujuan-tujuan tertentu.

Hasil penelitian tersebut tentunya menjadi suatu kekuatan yang dapat bersinergi dalam konteks bimbingan dan konseling berbasis budaya. Relevansi paparan data tentunya koheren dengan gagasan pendekatan konseling model KIPAS. Mappiare-AT (2017) konseling berbasis budaya model KIPAS mereduksi beberapa sub-tema dalam orientasi SOSIAL, diantaranya: (1) Situasi interaksi, dimana melalui kegiatan permainan Tangkap Lokam siswa akan mampu menjalin hubungan sosial baik dalam situasi formal dan non formal, (2) Output Interaksi, dimana melalui kegiatan permainan Tangkap Lokam hasil dengan tujuan yang positif dan interaksi produktif terkait kecakapan sosial siswa, (3) Saluran komunitas, dimana melalui kegiatan tersebut siswa mendapatkan banyak nilai kecakapan sosialnya yang dapat mengembangkan diri untuk menjalin hubungan dengan orang lain di sekolah, dan lingkungan masyarakat, (4) Internal vs ekstrenal arah komunikasi, dimana melalui permainan ini siswa dapat lebih terbuka dan ekspresif menjalin hubungan sosial dengan orang lain secara luwes, (5) Andalan diri, kaitannya dengan penerapan nilai kecakapan sosial yang berkembang didalam diri anak untuk mengutamakan kepentingan bersama dalam menjalin hubungan sosial, dan 6) Langgeng, kaitannya dengan kecakapan anak dalam berupaya menjalin interaksi untuk meningkatkan hubungan sosialnya dalam jangka panjang. Individu memerlukan kecakapan sosial dalam usahanya melakukan penyesuaian diri agar individu dapat melakukan adaptasi sosial dan memberikan respon-respon positif sesuai dengan harapan masyarakat dimana individu tersebut tinggal. Kecakapan sosial dipengaruhi oleh konteks atau situasi individu bertingkah laku, lingkungan mempengaruhi terbentuknya kebudayaan, selanjutnya kebudayaan mempengaruhi terbentuknya perilaku sosial (Triandis, 2004).

\section{PEMBAHASAN}

Subtema bahasan yang kedua berkenaan dengan kematangan karier siswa ialah tema bahasan KERJA yaitu: (1) Kaji kondisi khusus pribadi, (2) Elaborasi fakta diri, (3) Ramupadu peluang-kerja dan pengharapan orang berpengaruh, (4) Jajak padukan fakta-diri dan tuntutan dunia kerja, (5) Antisipasi kebermaknaan kerja dan kepuasan kerja kelak (MappiareAT.,2017). Hal ini merupakan upaya memenuhi kebutuhan tentang persiapan kerja peserta didik mengenai perencananan masa depan, latihan-latihan identifikasi klarifikasi ciri-ciri pribadi, latihan-latihan pembuatan pilihan dan pengambilan keputusan pekerjaan yang cocok dan sesuai dengan hati nurani. Crites (1986) memperjelas bahwa kematangan karier individu ialah kemampuan dalam mengambil suatu keputusan karier yang meliputi penetapan tujuan, pilihan yang realistis dan konsisten. Kematangan karier mengarah pada pengenalan karier secara menyeluruh, diawali dengan mengenali potensi diri, memahami lapangan kerja yang sebenarnya, perencanaan sampai dengan menentukan pilihan yang tepat. Pada tingkat global, diasumsikan bahwa semakin baik pengetahuan mengenai pekerjaan dan perencanaan karier, maka semakin baik tingkat kematangan karier individu (Jawarneh, 2016). Berdasarkan paparan data yang diperkuat oleh teori dan jurnal pendukung hasil penelitian, dipahami bahwa sistem nilai yang dianut oleh masyarakat Bengkulu, Tarakan, Madura khususnya dan 
Indonesia secara umum sejatinya dapat digunakan sebagai teknik konseling berbasis budaya sebagai upaya membantu mengatasi problematik sosial dan karier siswa dalam segi praktislapangan. Bimbingan dan konseling perlu dijalankan dengan pertimbangan sosial-budayareligius, penuh kekerabatan, kolaborasi, ditandai dengan keluwesan, kebebasan, dan meluangkan berkembangnya kreativitas, serta diisi dengan penerapan ajaran agama.

\section{KESIMPULAN DAN SARAN}

Konseling karier model KIPAS hakikatnya merupakan suatu kerangka kerja yang dirancang dan disusun agar dapat beradaptasi dengan konteks lingkungan sosial-budaya (struktur dan pranata) sekolah dan keadaan psikologis siswa di Indonesia. Strategi/teknik khusus yang digunakan mengacu pada sistem nilai budaya Tarakan, Bengkulu dan Madura. Implementasinya tidak terbatas pada tiga budaya tersebut, namun dapat diterapkan di seluruh Indonesia dengan menyesuaikan keragaman dan keunikan budaya siswa/konseli. Hal yang perlu dicermati untuk selanjutnya ialah berupaya mengkaji secara mendalam serta terarah sistem nilai yang terkandung dalam setiap budaya baik falsafah budaya, pepatah, pengharapan, permainan rakyat, pantun, dan lain-lain sebagai suatu teknik konseling berbasis budaya nusantara.

\section{DAFTAR RUJUKAN}

Bandura, A. 1977. Self-efficacy: Toward a Unifying Theory of Behavioral Change. Psychological Review, Vol 84 (2): 191-215.

Bandura, A. 1993.Perceived Self-Efficacy in Cognitive Development and Functioning.Educational Phychologist, Vol 28 (2): 117-148.

Bandura, A. 1994. Self-Efficacy. Encyclopedia of Human Behavior, Vol 4: 71-81.

Bandura, A. 1998.Personal and Collective Efficacy in Human Adaptation and Change. Hove, UK: Psychology Press.

Bandura, A., Barbaranelli, C., Caprara, G.V., \& Pastorelli, C. 2001. Self-Efficacy Beliefs as Shapers of Children's Aspirations and Career Trajectories.Child Development, Vol 72 (1): 187-206.

Bandura, A. 2006. Self-Efficacy Beliefs of Adolescent.hlm 307-337, (Online), (http://www.uky.edu/ eushe2/BanduraPubs/BanduraGuide2006.pdf), diakses 19 Maret 2013.

Bandura, A. 2009. Self Efficacy in Changing Societies. New York: Cambridge University Press.

Betz, N.E. 2007. Career Self-Efficacy: Exemplary Recent Research and Emerging Directions. Journal of Career Assessment, Vol 15 (4): 403-422.

Bozgeyikli, H., Eroglu, S.E., \& Hamurcu, H. 2009. Career Decision Making Self-Efficacy, Career Maturity and Socioeconomic Status with Turkish Youth. Georgian Electronic Scientific Journal: Education Science and Psychology, No. 1 (14): 15-24. 
Brusokas, A. \& Malinauskas, R. 2014. Career self-efficacy among Lithuanian adolescents in sports schools. Procedia - Social and Behavioral Sciences, No. 116: 212-216.

Corey, M.; Corey, G; dan. Corey, C. 2014. Groups: Process and practice. 9th $^{\text {th }}$. Belmont, CA: Brooks/Cole.

DeLucia-Waack, J.L. 2006. Leading Psychoeducational Groups. California: Sage Publications, Inc.

Feehan, P.F. \& Johnston, J.A. 1999. The Self-Directed Search and Career SelfEfficacy.Journal of Career Assessment, Vol 7 (2): 145-159.

Hanggara, G.S. 2016.Keefektifan "Proses Guru” Sebagai Teknik Bimbingan Kelompok Dalam Meningkatkan Pengambilan Keputusan Karier Siswa SMK. Jurnal Kajian Bimbingan dan Konseling.Vol. 1(4): 148-157.

Nursalim, M. 2013. Pengembangan Media Bimbingan dan Konseling. Jakarta: PT Indeks.

Remer, B. 2007. Reflective Practice: Learning from Real-World Experience. Dalam Silberman, M, (ed). The Handbook of Experiential Learning.San Fransisco: John Wiley \& Sons. Inc.

Santoso, D.B. 2011.Dasar-dasar Bimbingan dan Konseling. Malang: Fakultas IImu Pendidikan Universitas Negeri Malang.

Schon, D.A. 1983. The Reflective Practitioner: How Professionals Think in Action. USA: Basic Book.

Silberman, M. 2007. The Handbook of Experiential Learning.San Fransisco: John Wiley \& Sons. Inc. 